\title{
Expressão do gene da leptina e seu receptor Ob-Rb no parênquima mamário de novilhas leiteiras
}

\author{
Betina Joyce Lew ${ }^{1}$, Mauro Dal Secco de Oliveira ${ }^{2}$, Marina Vieira de Carvalho ${ }^{3}$, José Esler de \\ Freitas Júnior ${ }^{3}$, Francisco Palma Rennó ${ }^{3}$

\footnotetext{
${ }^{1}$ Department of Animal Science, Michigan State University, East Lansing, Michigan, USA.

2 Departamento de Zootecnia, Faculdade de Ciências Agrárias e Veterinárias, UNESP, Campus de Jaboticabal, São Paulo, Brasil.

${ }^{3}$ Departamento de Nutrição e Produção Animal, Faculdade de Medicina Veterinária e Zootecnia, USP, Campus de Pirassununga, São Paulo, Brasil.
}

RESUMO - Objetivou-se com este trabalho avaliar os efeitos de uma dieta de alto nível de energia e proteína combinada com a aplicação de bST no perfil de expressão dos genes da leptina e de seu receptor Ob-Rb no parênquima mamário de novilhas leiteiras. Foram utilizadas amostras de parênquima mamário de 32 novilhas holandesas distribuídas aleatoriamente em quatro tratamentos $(n=8)$ : dieta com alto ou baixo teor de energia e proteína combinada ou não com a aplicação de bST. O delineamento utilizado foi em blocos casualizados com arranjo de tratamentos em esquema fatorial $2 \times 2$. A extração do RNA total das amostras de tecido foi feita e o nível de expressão gênica foi analisado por qRT-PCR utilizando-se o gene da glicuronidase $\beta$ como controle, pelo método $2^{-\Delta \Delta \mathrm{Ct}}$. Animais que receberam a dieta com alto conteúdo de energia e proteína apresentaram maior expressão de mRNA de leptina, com aumento de 56\%, e menor expressão de mRNA do receptor Ob-Rb, com redução de $18 \%$. Por outro lado, a aplicação de bST resultou em diminuição da expressão do mRNA de leptina e do receptor Ob-Rb em $74 \%$ e $23 \%$, respectivamente. Não houve interação entre dieta e aplicação de bST. O aumento na expressão de leptina pode explicar, ao menos em parte, os efeitos negativos da dieta de alta energia e proteína, oferecida no período pré-púbere, sobre a produção de leite de novilhas leiteiras.

Palavras-chave: bST, energia, glândula mamária, nutrição

\section{Leptin and leptin receptor $\mathrm{Ob}-\mathrm{Rb}$ gene expression in mammary parenchyma of dairy heifers}

\begin{abstract}
The objective of this study was to examine the effects of a diet with high level of energy and protein, combined with bST injections, on leptin and leptin-receptor (Ob-Rb) gene expression profile in the mammary parenchyma of dairy heifers. Mammary parenchyma samples from 32 Holstein heifers, randomly assigned to one of four treatments ( $\mathrm{n}=8$ ), were utilized: high or low energy and protein diet, with or without bST injection. The experiment was designed in randomized blocks and arranged in a $2 \times 2$ factorial arrangement. Total RNA was extracted from tissue samples and gene expression profile was tested in qRT-PCR, against glucuronidase $\beta$ as a control, using the $2^{-\Delta \Delta C t}$ method. Animals receiving the diet with high level of energy and protein had higher leptin mRNA expression, with an increase of $56 \%$, and lower leptin receptor Ob-Rb mRNA expression, with a decrease of $18 \%$. On the other hand, bST injection decreased leptin mRNA and receptor Ob-Rb mRNA expression in $74 \%$ and $23 \%$, respectively. There was no interaction between diet and bST injection. The increase in leptin expression can explain, at least in part, the detrimental effects caused by diets rich in energy and protein, offered during the prepubertal period, in future milk production of dairy heifers.
\end{abstract}

Key Words: bST, energy, mammary gland, nutrition

\section{Introdução}

Dietas de alta energia aumentam o ganho de peso médio diário (GMD) de novilhas pré-púberes, reduzindo a idade à puberdade (IP) e ao primeiro parto e aumentando a produtividade da pecuária leiteira (Patterson et al., 1992; Davis Rincker et al., 2008). Entretanto, ganhos maiores que $0,8 \mathrm{~kg} \mathrm{PV} / \mathrm{d}$ podem reduzir a produção de leite desses animais (Waldo \& Capuco, 1992), devido ao acúmulo excessivo de gordura no úbere (Swanson, 1960) e a alterações hormonais que prejudicam o desenvolvimento mamário (Sejrsen \& Purup, 1997), processo complexo de proliferação e diferenciação celular, regulado por hormônios que interagem localmente com fatores de crescimento (Akers et al., 2000).

Vários autores procuraram elucidar os mecanismos do desenvolvimento mamário de novilhas de alto GMD tratadas 
com somatotropina bovina (bST) (Weber et al., 1999; Radcliff et al., 2000; Berry et al., 2001), no entanto, esses mecanismos continuam obscuros. A análise das alterações moleculares presentes nesta situação ajudaria na compreensão dos fatores endócrinos envolvidos, permitindo a aplicação de novas técnicas de manejo para reduzir a IP, sem prejuízo da produção leiteira.

Novilhas com alto GMD possuem baixa somatotropina sérica, hormônio relacionado ao crescimento corporal e à mamogênese (Sejrsen et al., 1983; Sejrsen \& Purup, 1997) e que regula diretamente os estoques de tecido adiposo dos ruminantes, pelo aumento da resposta dos tecidos aos estímulos lipolíticos (Roche, 2009). Sabe-se que a administração de bST em novilhas pré-púberes aumenta a taxa de crescimento corporal e a massa de parênquima mamário e reduz a quantidade de gordura na carcaça (Radcliff et al., 1997; Radcliff et al., 2000; Vestergaard et al., 1993).

Por outro lado, o aumento da gordura corporal eleva a concentração sérica de leptina (Chilliard et al., 2005), hormônio proteico produzido principalmente por adipócitos, relacionado a processos metabólicos como consumo, divisão celular e reprodução (Zhang et al., 1994; Houseknecht et al., 1998), e que pode estar envolvida nos efeitos deletérios da nutrição sobre a mamogênese bovina (Silva et al., 2008).

A leptina atua por meio da ligação com receptores de membrana específicos, sendo que a forma longa do receptor $(\mathrm{Ob}-\mathrm{Rb})$ é expressa nas células epiteliais mamárias de bovinos, apesar de em pequena quantidade (Silva et al., 2002a; Chelikani et al., 2003; Thorn et al., 2006). A relação entre a quantidade de proteína e a síntese de receptores varia entre tecidos e situações endócrinas e metabólicas, podendo seguir um padrão de resposta direta ou inversa (up ou down regulation).

Assim, dietas de alta energia reduzem a concentração de somatotropina sérica, aumentando a porcentagem de gordura corporal e a concentração, tanto da leptina sérica quanto da localizada no tecido mamário. Por outro lado, o tratamento com somatotropina sérica atenua esse efeito (Blache et al., 2000; Davis Rinker et al., 2008; Thorn et al., 2006). Desta forma, a interação entre as duas moléculas pode estar relacionada ao estímulo do bST no desenvolvimento mamário e, uma vez que o receptor de leptina está presente no tecido mamário de animais em crescimento, é possível que ela esteja envolvida nesse processo e nos efeitos deletérios do excesso de gordura no úbere.

O objetivo neste trabalho foi determinar o efeito da administração de bST e da dieta de alta energia e proteína na expressão gênica da leptina e seu receptor $\mathrm{Ob}-\mathrm{Rb}$ no parênquima mamário de novilhas leiteiras.

\section{Material e Métodos}

Utilizaram-se amostras de parênquima mamário de 32 novilhas da raça Holandesa, com PV médio de $126 \mathrm{~kg}$ e 120 dias de idade, coletadas em experimento prévio conduzido no Departamento de Ciências Animais da Michigan State Unversity (MSU).

Uma descrição detalhada do manejo dos animais, da composição das dietas e das coletas de tecido foi publicada por Radcliff et al. (1997). Em resumo, utilizou-se um delineamento experimental em blocos casualizados, com oito blocos com quatro animais cada, formados de acordo com o PV. Os tratamentos foram arranjados em esquema fatorial $2 \times 2$, com duas dietas (uma de alto e outra de baixo conteúdo energético-proteico) combinadas ou não à aplicação de bST, totalizando quatro tratamentos, cada um com oito repetições. As dietas foram formuladas para proporcionar ganho de peso médio diário (GMD) de $0,8 \mathrm{~kg}$ $\mathrm{PV} / \mathrm{d}$ e 1,2 kg PV/dia, respectivamente, e foram fornecidas à vontade uma vez ao dia, pela manhã, na forma de ração completa. De modo geral, as dietas com baixo e alto conteúdo de energia e proteína apresentavam valores de energia líquida de mantença de 1,17 e 1,83 Mcal/kg MS, energia líquida de crescimento de 0,57 e 1,20 Mcal/kg MS e proteína bruta (PB) de 16,3 e 19,4\% da MS, respectivamente. As novilhas dos dois grupos com aplicação de bST receberam injeções intramusculares diárias de $25 \mathrm{mg}$ bST/100 kg PV (Pharmacia \& Upjohn Inc., Kalamazoo, MI) (Radcliff et al., 1997).

Todas as novilhas foram abatidas na fase luteal inicial do quinto ciclo estral, em média 71 dias após o início da puberdade, o que correspondeu a uma média de 276 e 218 dias após o início do experimento para os grupos recebendo dieta de baixa e alta energia e proteína, respectivamente. Considerou-se início da puberdade quando a concentração sérica de progesterona tornouse maior que $1 \mathrm{ng} / \mathrm{ml}$ em três amostras de sangue consecutivas (Spicer et al., 1981). As metades esquerdas das glândulas mamárias dos animais, separadas no ligamento suspensório médio, foram congeladas em mistura de gelo seco e etanol $95 \%$ e cortadas em fatias transversais de 5 a $10 \mathrm{~mm}$. O parênquima dessas amostras foi isolado do tecido adiposo, congelado em nitrogênio líquido, pesado e triturado até formar um pó fino, o qual foi armazenado em freezer a $-80^{\circ} \mathrm{C}$ para posterior análise (Radcliff et al., 1997). 
O RNA total foi extraído e purificado a partir de $100 \mathrm{mg}$ de parênquima mamário, utilizando-se o kit Ribopure (Ambion), segundo instruções do fabricante. Resumidamente, as amostras foram homogeneizadas em $1 \mathrm{ml}$ de reagente TRI, contendo fenol e tiocianato de guanidina, para lisar as células e inativar as nucleases. A seguir, adicionaram-se $100 \mu 1$ de bromocloropropano (BCP) a cada tubo. Os tubos foram vortexados, incubados em temperatura ambiente por 5 minutos e centrifugados a $12.000 \mathrm{~g}$ por $10 \mathrm{~min}$ a $4{ }^{\circ} \mathrm{C}$, havendo separação da mistura em uma fase orgânica avermelhada, no fundo do tubo (fenol-BCP), uma fase intermediária e uma fase aquosa superior incolor. Em um novo tubo de microcentrífuga de $1,5 \mathrm{ml}$, adicionaram-se $400 \mu \mathrm{l}$ da fase aquosa e $200 \mu \mathrm{lde}$ etanol $100 \%$. As amostras foram transferidas para tubos coletores devidamente identificados, contendo filtros de fibra de vidro, e foram centrifugadas a $12.000 \mathrm{~g} \mathrm{em}$ temperatura ambiente por 30 segundos, até que todo o volume tivesse atravessado o filtro. A parte líquida foi descartada e o filtro, com o RNA aderido, foi recolocado no mesmo tubo coletor e lavado duas vezes com $500 \mu 1$ de solução de lavagem e centrifugação como citado acima, para retirada de contaminantes. Após a lavagem, o filtro foi transferido para novo tubo coletor, ao qual foram adicionados $100 \mu \mathrm{l}$ de tampão de eluição. Após incubação em temperatura ambiente por 2 minutos e centrifugação por 30 segundos, o RNA total foi recuperado no tampão de eluição.

Após a extração, a concentração do RNA total recuperado foi determinada por espectrofotometria a $260 \mathrm{~nm}$ e o grau de pureza das amostras foi determinado pela razão entre as leituras de absorbância realizadas em 260 e 280 nm. A integridade do material foi analisada pela razão entre as subunidades de RNA ribossomal (rRNA) $28 \mathrm{~S}$ e $18 \mathrm{~S}$, em equipamento BioAnalyzer 2100 (Agilent Technologies, Palo Alto, CA), a partir de $1,0 \mu 1$ de solução contendo de 100 a $500 \mathrm{ng}$ de RNA. As amostras foram consideradas de boa qualidade quando a relação entre os picos $28 \mathrm{~S}$ e $18 \mathrm{~S}$ foi $\geq 0,9$.

Moléculas de DNA fita simples (cDNA) foram produzidas a partir do RNA, utilizando-se a enzima Transcriptase
Reversa RNAse $\mathrm{H}^{-}$SuperScript II (Invitrogen, Carlsbad, CA), segundo instruções do fabricante. Adicionaram-se $5 \mu \mathrm{g}$ de RNA total, $0,5 \mu \mathrm{g}$ oligo(dT) ${ }_{18}$ primer e $1 \mu \mathrm{dNTP}$ (10 mM cada), em volume final de $12 \mu 1$. Após incubação a $65^{\circ}$ por 5 minutos, a reação foi resfriada em gelo por 1 minuto e adicionada de $4 \mu 1$ de tampão RT $5 \mathrm{X}, 4 \mu 1$ de $\mathrm{MgCl}_{2-} 5 \mathrm{mM}$ e $2 \mu 1 \mathrm{DTT} 0,1 \mathrm{M}$, em volume final de $20 \mu \mathrm{l}$. A reação foi incubada a $42^{\circ} \mathrm{C}$ por 2 minutos e adicionada, então, de $1 \mu \mathrm{l}(200$ U) da enzima SuperScript-RT. A transcrição reversa foi realizada a $42^{\circ} \mathrm{C}$ por 50 minutos e a inativação da reação foi realizada a $70^{\circ} \mathrm{C}$ por 15 minutos. A fita de RNA complementar foi, então, removida do cDNA pela adição de $1 \mu \mathrm{l}(2 \mathrm{U})$ de RNAse $\mathrm{H}$ e incubação a $37^{\circ} \mathrm{C}$ por 20 minutos. A concentração e integridade do cDNA foi determinada em espectrofotômetro NanoDrop ND-1000 (NanoDrop Technologies, Inc., Rockland, DE), a partir de $1 \mu 1$ de solução.

A expressão dos genes da leptina e do receptor Ob-RB em resposta às dietas e à aplicação de bST foi analisada por PCR quantitativo em tempo real (qRT-PCR), em equipamento Applied Biosystems 7000 DNA Sequence Detection System (Perkin Elmer Corp., Foster City, CA), utilizando-se SYBR Green PCR Master Mix (Applied Biosystems, Foster City, CA). Os primers (Tabela 1) para os genes da leptina, receptor $\mathrm{Ob}-\mathrm{Rb}$ e controle (Glicuronidase $\beta$ ) foram desenhados com auxílio do software Primer Express (Applied Biosystems, Foster City, CA).

A eficiência de amplificação foi testada por meio de uma curva de diluição com diferentes concentrações cDNA $(0,1-100 \mathrm{ng}) \mathrm{de}$ cada gene. Além disso, foram testadas diferentes concentrações dos primers $(150,300,600 \mathrm{e}$ $900 \mathrm{nM}$ ), para determinar a concentração ótima a ser utilizada, sendo escolhida a concentração de $300 \mathrm{nM}$ (150 nM de cada, reverso e forward) para todos os primers.

No qRT-PCR, o gene-alvo é amplificado junto com um gene constitutivo controle. Para identificação do melhor gene controle, cinco diferentes genes constitutivos foram testados (glicuronidase $\beta-$ GUS; proteína ribossomal grande $-\mathrm{P} 0$; fosfoglicerato quinase $2-\mathrm{PGK}$; ciclofilina -

Tabela 1 - Sequências de primers utilizados na amplificação por PCR

\begin{tabular}{|c|c|c|}
\hline Gene & Sequência dos primers $\left(5^{\prime} \rightarrow 3^{\prime}\right)$ & $\mathrm{N}^{\mathrm{o}}$ de acesso GenBank \\
\hline GUS $^{1}$ & $\begin{array}{l}\text { Forward: TGTCATCGCACACAGAGCAA } \\
\text { Reverso: CACAAAATCCAGGTGAGAAGCTT }\end{array}$ & NM 001083436.1 \\
\hline Leptina & $\begin{array}{l}\text { Forward: GGGTGATTTCAGAGCCTTTGG } \\
\text { Reverso: CCATCGTATGTTGTGTGGGAAT }\end{array}$ & NM 173928.2 \\
\hline $\mathrm{Ob}-\mathrm{Rb}$ & $\begin{array}{l}\text { Forward: GGGCACATCCAAGCATTAAAA } \\
\text { Reverso: GGCCGGCATCAAAGCTTT }\end{array}$ & NM $\quad 001037462.1$ \\
\hline
\end{tabular}

${ }^{1}$ Glicuronidase $\beta$ (Controle) 
CYP e RNA ribossomal 18S - 18S) e comparados por meio das médias dos valores de $\mathrm{Ct}$ (threshold cicle) obtidos de quatro amostras por tratamento, de acordo com Vandesompele et al. (2003). O gene GUS apresentou maior estabilidade de expressão nos diferentes tratamentos, de forma que os dados de $\mathrm{Ct}$ dos genes de interesse foram normalizados em relação ao gene GUS utilizando-se as diferenças das médias de três repetições de cada amostra contra o controle (GUS).

As reações do qRT-PCR foram realizadas em triplicatas em duas placas MicroAmp Optical 96-Well (Applied Biosystems, Foster City, CA), uma para cada um dos genes testados (leptina ou receptor $\mathrm{Ob}-\mathrm{Rb}$ ) mais o gene controle, sendo que cada placa consistiu de 16 diferentes amostras (4/tratamento), totalizando 48 poços para o gene de interesse e 48 para o controle. Em cada poço, foram adicionados $300 \mathrm{nM}$ de primer reverso e forward (150 $\mathrm{nM}$ de cada), $30 \mathrm{ng}$ da amostra de cDNA, 12,5 $\mu 1$ de SYBR Green e quantidade suficiente de água livre de RNAse para volume de $25 \mu \mathrm{l}$, sendo as placas cuidadosamente fechadas com cobertura adesiva MicroAmp (Applied Biosystems, Foster City, CA). O programa de amplificação foi realizado como descrito na Tabela 2 e os valores de $\mathrm{Ct}$ foram obtidos com auxílio do software ABI Prism 7000 versão 1.1 (Applied Biosystems).

Os resultados foram avaliados pelo método de quantificação relativa $2^{-\Delta \Delta C t}$, utilizado para verificar possíveis variações na expressão relativa dos genes da

Tabela 2 - Programa de amplificação do cDNA

\begin{tabular}{lccc}
\hline Etapas & Temperatura & Tempo & $\mathrm{N}^{\circ}$ de ciclos \\
\hline Desnaturação inicial & $95{ }^{\circ} \mathrm{C}$ & 2 minutos & 1 \\
Amplificação & & & 40 \\
Desnaturação & $95{ }^{\circ} \mathrm{C}$ & 10 segundos & \\
Anelamento & $58{ }^{\circ} \mathrm{C}$ & 10 segundos & \\
Extensão & $72{ }^{\circ} \mathrm{C}$ & 15 segundos & \\
Resfriamento & $4{ }^{\circ} \mathrm{C}$ & indeterminado & \\
\hline
\end{tabular}

leptina e do receptor $\mathrm{Ob}-\mathrm{RB}$ entre os tratamentos, de acordo com a seguinte equação (Livak \& Schmittgen, 2001):

$\Delta \Delta \mathrm{Ct}=\left(\mathrm{Ct}_{\mathrm{GTESTE}}-\mathrm{Ct}_{\mathrm{GUS}}\right)_{\mathrm{TX}}-\left(\mathrm{Ct}_{\mathrm{GTESTE}}-\mathrm{Ct}_{\mathrm{GUS}}\right)_{\mathrm{TY}}$ em que $\mathrm{Ct}_{\mathrm{GTESTE}}=$ ciclo de amplificação do cDNA do gene testado (média das três repetições); $\mathrm{Ct}_{\mathrm{GUS}}=$ ciclo de amplificação do cDNA do gene controle (GUS) (média das três repetições); $\mathrm{TX}=$ tratamento testado $\mathrm{X} ; \mathrm{TY}=$ tratamento testado Y.

Os dados foram submetidos à análise de variância pelo procedimento GLM do SAS (versão 8.0). Após normalização contra o gene controle GUS, os tratamentos foram normalizados contra o grupo controle (LC) e são apresentados como média \pm erro padrão da média. Foram testados os efeitos de dieta, administração de bST e interação entre os dois. Para a análise dos efeitos da aplicação de bST avaliou-se o contraste entre os grupos $\mathrm{HB}+\mathrm{LB}$ e $\mathrm{HC}+\mathrm{LC}$, enquanto os efeitos da dieta foram analisados através do contraste entre os grupos HC+HB e LB+LC. Adotou-se nível de significância de 5\%.

\section{Resultados e Discussão}

Não houve interação entre dieta e aplicação de bST ( $\mathrm{P}>0,05 ;$ Tabela 3 ). A dieta de alta energia e proteína aumentou a expressão de leptina no parênquima mamário em $56 \%$ e diminuiu a expressão do receptor Ob-Rb em $18 \%$ $(\mathrm{P}<0,03)$, quando comparado com os grupos recebendo a dieta de baixa energia e proteína (Tabela 3, Figura 1). Por sua vez, a administração de bST diminuiu em $74 \%$ a expressão gênica de leptina e em $23 \%$ a expressão do receptor $\mathrm{Ob}-\mathrm{Rb}$ $(\mathrm{P}<0,01)$ no parênquima mamário, quando comparados aos animais que não receberam bST (Tabela 3; Figura 2).

Segundo Silva et al. (2002b), novilhas leiteiras prépúberes submetidas a dietas que propiciam taxas de crescimento superiores a $1 \mathrm{~kg} \mathrm{PV} / \mathrm{d}$ apresentam, em média, $20 \%$ de redução no desenvolvimento do parênquima mamário. Esse efeito parece estar relacionado a mudanças hormonais decorrentes desse tipo de manejo, por exemplo, redução na concentração de somatotropina circulante (Sejrsen et al., 1983). A somatotropina tem efeito indireto

Tabela 3 - Expressão gênica da leptina e seu receptor OB-Rb no parênquima mamário

\begin{tabular}{|c|c|c|c|c|c|c|c|c|c|}
\hline & \multicolumn{4}{|c|}{$-\Delta \Delta \mathrm{Ct}$} & \multirow{2}{*}{\multicolumn{2}{|c|}{ Fold change 3}} & \multicolumn{3}{|c|}{ Valor de $\mathrm{P}^{4}$} \\
\hline & \multicolumn{2}{|c|}{ Dieta $^{1}$} & \multicolumn{2}{|c|}{$\mathrm{bST}^{2}$} & & & & & \\
\hline Genes & $\mathrm{H}$ & $\mathrm{L}$ & B & $\mathrm{C}$ & Dieta & bST & Dieta & $\mathrm{bST}$ & Interação \\
\hline Leptina & 0,350 & $-0,293$ & $-0,371$ & 0,427 & 1,563 & $-1,74$ & 0,025 & 0,007 & 0,448 \\
\hline OB-Rb & $-0,333$ & $-0,093$ & $-0,362$ & $-0,064$ & $-1,180$ & $-1,229$ & 0,027 & 0,007 & 0,288 \\
\hline
\end{tabular}

${ }^{1}$ Efeitos das dietas de alta $(\mathrm{H})$, energia (HC) e proteína (HB), e baixa (L) energia (LC) e proteína (LB).

${ }^{2}$ Efeitos da aplicação da somatotropina (bST) (B) e sem aplicação de bST (C).

${ }^{3}$ Fold change (variação da expressão gênica) devido ao efeito de dieta (HC+HB vs LC+LB) e da aplicação de bST (HB+LB vs HC+LC), após normalização pelo método de $2^{-\Delta \Delta \mathrm{Ct} \text {. }}$

${ }^{4}$ Probabilidade de efeito de dieta (contraste LC+LB versus HC+HB), da aplicação de bST (contraste LC+HC vs LB+HB) e da interação entre dieta e bST. 


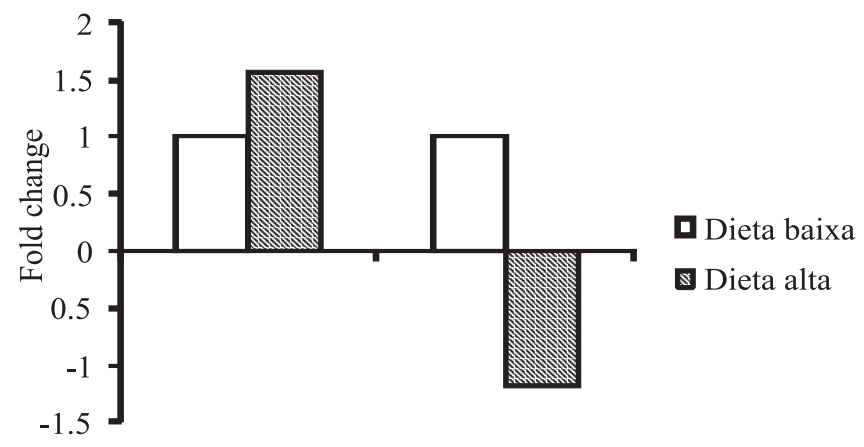

Leptina $\quad \mathrm{Ob}-\mathrm{Rb}$

Figura 1 - Impacto da dieta na variação da expressão gênica (fold change) da leptina e do receptor $\mathrm{Ob}-\mathrm{Rb}$ no parênquima mamário.

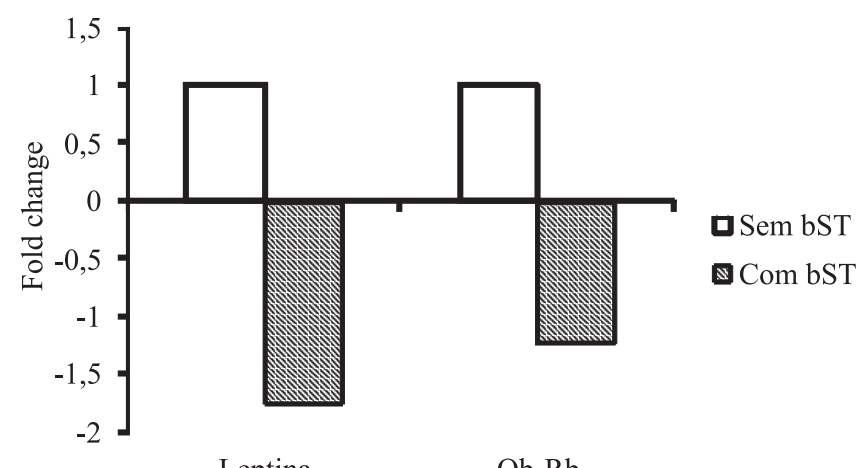

Leptina $\quad \mathrm{Ob}-\mathrm{Rb}$

Figura 2 - Impacto do bST na variação na expressão gênica (fold change) da leptina e do receptor $\mathrm{Ob}-\mathrm{Rb}$ no parênquima mamário.

sobre a glândula mamária, em função da ação do fator de crescimento semelhante à insulina do tipo I (IGF-I) no tecido (Cohick, 1998), uma vez que receptores para o mesmo encontram-se nas células do estroma intralobular, vasos sanguíneos e capilares da referida glândula. Sabe-se também que o mesmo também e um mediador local do crescimento e desenvolvimento da glândula mamária (Glimm, 1992).

Além da maior expressão de leptina no parênquima mamário, as novilhas recebendo a dieta de alta energia e proteína apresentaram também aumento na concentração plasmática de IGF-I (previamente relatado por Radcliffet al., 2004) e na quantidade de gordura extra parenquimal (Radcliff et al., 1997). Sabe-se que, ao contrário de experimentos in vitro, em que o IGF-I estimula a proliferação de células mamárias (Purup et al., 1993; Purup et al., 1995), em animais com crescimento acelerado (alto GMD), níveis baixos de somatotropina e altos de IGF-I circulantes levam à diminuição do desenvolvimento mamário (Sejrsen et al., 2000). Após a aplicação do somatotropina, sua concentração aumenta no plasma com intervalo de três dias, permanecendo significativamente alta por volta de sete dias, alcançando níveis basais ate 14 dias após aplicação. A concentração de IGF-1 no plasma aumenta gradualmente no início do tratamento, retornando para níveis basais por volta de 16 a 18 dias após aplicação do bST. Assim, o aumento de leptina encontrado neste trabalho sugere que a participação dessa proteína nos mecanismos que impedem que o aumento de IGF-I no plasma de animais em crescimento acelerado leve a um aumento no desenvolvimento mamário, uma vez que a leptina reduz a síntese de DNA das células epiteliais mamárias, antagonizando a proliferação in vitro, induzida pelo IGF-I, de células MAC-T (Silva et al., 2002a), células epiteliais mamárias imortalizadas de bovinos, que proliferam na presença de IGF-I (Huynh et al., 1991). Neste sentido, McFadden \& Cockrell (1993) demonstraram que a adição de tecido adiposo em culturas de células epiteliais mamárias inibiu a proliferação celular, reforçando a suposição de que o acúmulo excessivo de gordura no úbere prejudica o desenvolvimento mamário. Sejrsen et al. (2000) observaram também que culturas de tecido mamário coletado de animais alimentados com níveis elevados de proteína e energia apresentaram menor resposta proliferativa ao IGF-I em comparação a cultura do tecido de animais alimentados com menores níveis de proteína e energia. Em conjunto, esses dados sugerem que a leptina sintetizada localmente na glândula mamária é um dos fatores envolvidos no processo de desenvolvimento mamário, antagonizando o aumento de desenvolvimento parenquimal induzido pelo IGF-I em animais pré-púberes submetidos a taxas de crescimento acelerado.

A hipótese de que a leptina esteja envolvida nos mecanismos pelos quais o aumento de IGF-I em animais alimentados com níveis elevados de proteína e energia não é acompanhado por aumento no desenvolvimento mamário é reforçada pela diminuição na expressão de leptina nos animais tratados com bST, como demonstrado neste estudo (Tabela 3). Essa diminuição coincidiu com aumento do IGF-I plasmático (Radcliff et al., 2004), da massa parenquimal e com a diminuição na quantidade de gordura mamária, relatadas previamente por Radcliff et al. (1997). Sejrsen et al. (1986) já haviam relatado aumento na massa total de parênquima mamário e redução na quantidade de tecido adiposo na glândula mamária de novilhas leiteiras tratadas com bST. Da mesma forma, Radcliff et al. (1997) relataram aumento na quantidade total de DNA e RNA no parênquima, além de aumento no número de células epiteliais na glândula mamária de novilhas tratadas com bST. Isozaki et al. (1999) relataram diminuição nos níveis de mRNA de leptina na gordura visceral de ratos Zucker obesos, geneticamente modificados para expressão de receptores nãofuncionais de leptina, tratados com somatotropina. 
Quando comparados ao grupo alimentado com a dieta controle, sem administração de bST, os animais alimentados com a dieta de alta energia e proteína sem administração de bST apresentaram aumento de $80 \%(\mathrm{P}<0,05)$ na expressão gênica da leptina, entretanto, a expressão do receptor $\mathrm{Ob}-\mathrm{Rb}$ não se alterou $(\mathrm{P}>0,05)$ (Tabela 4). A administração de bST não alterou a expressão gênica das novilhas em dieta controle $(\mathrm{P}>0,05)$, porém, nas novilhas recebendo dieta de alta proteína e energia, houve diminuição de mais de duas vezes $(\mathrm{P}<0,05)$ na expressão gênica de leptina e de $27 \%$ $(\mathrm{P}<0,05)$ na expressão gênica do receptor $\mathrm{Ob}-\mathrm{Rb}$. As novilhas alimentadas com a dieta de alta energia e proteína, com aplicação de bST apresentaram redução de $32 \%(\mathrm{P}<0,05)$ na expressão gênica de $\mathrm{Ob}-\mathrm{Rb}$ se comparadas àquelas alimentadas com a dieta de baixa energia e proteína, com aplicação de bST, não havendo alteração na expressão de leptina (Tabela 4).

Apesar de não ter havido interação entre a dieta e aplicação de bST, os efeitos do bST na diminuição dos níveis de mRNA de leptina foram mais evidentes nos animais que receberam as dietas com níveis proteicos e energéticos elevados (Tabela 4). Em concordância com trabalhos anteriores, em que indivíduos deficientes em somatotropina apresentaram redução na deposição de gordura no tecido adiposo (Deoer et al., 1995) e ratos Zucker obesos tratados com somatotropina apresentaram redução na quantidade de gordura do epidídimo (Isozaki et al., 1999), os resultados deste estudo indicam que a administração de bST atenua os efeitos das dietas ricas em proteína e energia no desenvolvimento mamário, provavelmente devido à sua ação lipolítica.

Com o aumento no mRNA de leptina no parênquima mamário de animais alimentados com dietas de altos níveis proteicos e energéticos, ocorre acúmulo local dessa proteína, tanto pela maior produção pelo tecido adiposo, presente em maior quantidade (Ehrhardt et al., 2000), como por uma provável síntese pelas células epiteliais (Chilliard et al., 2001; Smith \& Sheffield, 2002). Esse aumento pode ser um dos fatores que levam à posterior redução da produção leiteira de animais alimentados com dietas desse tipo. Radcliff et al. (2000) observaram redução de $12 \%$ na produção leiteira na primeira lactação de novilhas alimentadas com altos níveis de energia e proteína em comparação a uma dieta padrão. Apesar de ao abate os animais não terem apresentado diminuição na massa total de parênquima mamário (Radcliff et al., 1994), o acúmulo de gordura extra parenquimal na fase pré-púbere pode ter efeito carreador durante o desenvolvimento mamário na primeira gestação, por meio de efeito autócrino e parácrino da leptina na proliferação e diferenciação das células epiteliais durante essa fase do desenvolvimento mamário (Chilliard et al., 2001; Baratta, 2002).

Em ambos os casos, houve redução na expressão gênica do receptor de leptina Ob-Rb (Tabela 3). Em condições de subnutrição, por exemplo, a diminuição na concentração de leptina circulante é acompanhada por aumento na quantidade de receptores de leptina, tornando as células-alvo mais sensíveis à ação da proteína e sugerindo uma reação adaptativa de sobrevivência à restrição alimentar (Chilliard et al., 2001). Desta forma, a diminuição na expressão dos receptores de leptina nas células parenquimais sugere diminuição na sensibilidade dessas células à leptina. No caso das novilhas recebendo dieta de alta energia e proteína, essa diminuição pode explicar, em parte, o fato de os animais alimentados com dietas elevadas, mesmo tendo aumento na expressão de leptina, não ter apresentado diferença significativa no desenvolvimento parenquimal ao abate, e isso reforça a hipótese de um possível efeito carreador da deposição de gordura no úbere durante a fase pré-pubere do desenvolvimento mamário na posterior produção leiteira.

Por sua vez, a administração de bST parece diminuir os possíveis efeitos da leptina no desenvolvimento mamário, tanto pela diminuição da expressão da proteína como pela diminuição na expressão gênica de OB-Rb, diminuindo assim a sensibilidade das células epiteliais a essa proteína. Essa hipótese é suportada por trabalhos realizados durante as fases de gestação adiantada em ovelhas, em que o tecido adiposo regrediu completamente e houve diminuição acentuada na expressão gênica do receptor de leptina em células epiteliais (Laud et al., 1999).

Tabela 4 - Variação de expressão gênica da leptina e do receptor Ob-Rb entre os contrastes de maior interesse

\begin{tabular}{lcccc}
\hline & \multicolumn{2}{c}{ Leptina } & \multicolumn{2}{c}{ Ob-Rb } \\
\cline { 2 - 4 } Contrastes $^{1}$ & Fold change $^{2}$ & Valor de P & Fold $_{\text {change }}^{2}$ & Valor de P \\
\hline HC vs LC & 1,80 & 0,032 & $-1,05$ & 0,385 \\
LB vs LC & 1,08 & 0,142 & $-1,13$ & 0,209 \\
HB vs HC & $-2,01$ & 0,013 & $-1,27$ & 0,022 \\
HB vs LB & 1,01 & 0,279 & $-1,32$ & 0,008 \\
\hline
\end{tabular}

${ }^{1}$ LC: dieta de baixa energia e proteína, sem aplicação de bST; LB: dieta de baixa energia e proteína, com aplicação de bST (25 mg/100 kg PV, IM); HC: dieta de alta energia e proteína, sem aplicação de bST; HB: dieta de alta energia e proteína, com aplicação de bST ( $25 \mathrm{mg} / 100 \mathrm{~kg}$ PV, IM).

${ }^{2}$ Fold change (variação de expressão gênica) após transformação pelo método de 2 - $\Delta \Delta \mathrm{Ct}$. 


\section{Conclusões}

Durante a fase pré-púbere, o oferecimento de dietas com níveis protéico-energéticos elevados aumenta a quantidade de leptina no tecido mamário, prejudicando o desenvolvimento da glândula e podendo reduzir a posterior produção leiteira na primeira lactação. A administração de bST em novilhas pré-púberes diminui a produção de leptina no úbere, podendo atenuar os efeitos prejudiciais da dieta no desenvolvimento mamário.

\section{Agradecimentos}

Aos professores James Liesman e Michael John VandeHaar da Universidade de Michigan nos Estados Unidos da America pelos recursos concedidos para execução do projeto e o apoio científico na condução deste estudo.

\section{Referências}

AKERS, R.M.; McFADDEN, T.B.; PURUP, S. et al. Local IGF-I axis in peripubertal ruminant mammary development. Journal of Mammary Gland Biology and Neoplasia, v.5, p.43-51, 2000 .

BARATTA, M. Leptin - from a signal of adiposity to a hormonal mediator in peripheral tissues. Medical Science Monitor, v.8, p.282-292, 2002.

BERRY, S.D.; McFADDEN, T.B.; PEARSON, R.E. et al. A local increase in the mammary IGF-I:IGFBP-3 ratio mediates the mammogenic effects of estrogen and growth hormone. Domestic Animal Endocrinology, v.21, p.39-53, 2001.

CHILLIARD, Y.; BONNET, M.; DELAVAUD, C. et al. Leptin in ruminants: gene expression in adipose tissue and mammary gland, and regulation of plasma concentration. Domestic Animal Endocrinology, v.21, p.271-295, 2001.

CHILliaRD, Y.; DELAVAUD, C.; BONNET, M. Leptin in ruminants: Nutritional and physiological regulations in relation to energy metabolism. Domestic Animal Endocrinology, v.29, p.3-22, 2005.

COHICK, W.S. Role of insulin like growth factors and their binding protein in lactation. Journal of Dairy Science, v.81, n.6, p.1769-1777, 1998.

DEOER H.; BLOCK, G.J.; VAN DER VEEN, E.A. Clinical aspects of growth hormone deficiency in adults. Endocrine Review, v. 16, p.63-86, 1995 .

EHRHARDT, R.A.; SLEPETIS, R.M.; SIEGAL WILLOTT, J. et al. Development of a specific radioimmunoassay to measure physiological changes of circulating leptin in cattle and sheep. Journal of Endocrinology, v.166, p.519-528, 2000.

FAIN, J.N.; KOVACEV, V.P.; SCOW, R.O. Effect of growth hormone and dexamethasone on lipolysis and metabolism in isolated fat cells of the rat. Journal of Biological Chemistry, v.240, p.3522-3529, 1965

GIULIETTI, A.; OVERBERGH, L.; VALCKX, D. et al. An overview of real-time quantitative PCR: applications to quantify cytokine gene expression. Methods, v.25, p.386-401, 2001.

GLIMM, D.R.; BARACOS, V.E.; KENNELLY, J.J. Northern and in situ hybridization analyses of the effects of somatotropina on bovine mammary gene expression. Journal of Dairy Science, v.75, n.10, p.2687-2705, 1992.

GOODMAN, H.M. Multiple effects of growth hormone on lipolysis. Journal of Endocrinology, v.83, p.300-308, 1968.

HOUSEKNECHT, K.L.; BAILE, C.A.; MATTERI, R.L. et al. The biology of leptin: a review. Journal of Animal Science, v.76, p.1405-1420, 1998.

HUYNH, H.T.; ROBITALE, G.; TURNER, J.D. Establishment of bovine mammary epithelial cells (MAC-T): an in vitro model for bovine lactation. Experimental Cell Research, v.197, n.2, p.191-199, 1991.

ISOZAKI, O.; TSUSHIMA, T.; MIYAKAWA, M. et al. Growth hormone directly inhibits leptin gene expression in visceral fat tissue in fatty Zucker rats. Journal of Endocrinology, v.161, p.511-516, 1999.

KRISTENSEN, K.; PEDERSEN, S.B.; FISKER, S. et al. Serum leptin levels and leptin expression in growth hormone $(\mathrm{GH})$-deficient and healthy adults: influence of GH treatment, gender, and fasting. Metabolism, v.47, p.1514-1519, 1998.

LAUD, K.; GOURDOU, I.; BELAIR, L. et al. Detection and regulation of leptin receptor mRNA in ovine mammary epithelial cells during pregnancy and lactation. Febs Letters, v.463, p.194-198, 1999.

LIVAK, K.J.; SCHMITTGEN, T.D. Analysis of relative gene expression data using real-time quantitative PCR and the $2^{-\triangle \Delta C}$ T Method. Methods, v.25, p.402-408, 2001.

McFADDEN, T.B.; COCKRELL, D.C. Regulation of growth in cultured mammary epithelium from beef and dairy heifers. Proceedings of New Zealand Society of Animal Production, v.53, p.143-145, 1993

PATTERSON, D.J.; PERRY, R.C.; KIRACOFE, G.H. et al. Management considerations in heifer development and puberty. Journal of Animal Science, v.70, p.4018, 1992.

PURUP, S.; SEJRSEN, K.; FOLDAGER, J. et al. Effect of exogenous bovine growth hormone and ovariectomy on prepubertal mammary growth, serum hormones, and acute in vitro proliferative response of mammary explants from Holstein heifers. Journal of Endocrinology, v.139, p.19-26, 1993.

PURUP, S.; SEJRSEN, K.; AKERS, R.M. Effect of bovine GH and ovariectomy on mammary tissue sensitivity to IGF-I in prepubertal heifers. Journal of Endocrinology, v.144, p.153-158, 1995

RADCLIFF, R.P.; VANDEHAAR, M.J.; CHAPIN, L.T. et al. Effects of diet and injection of bovine somatotropin on prepubertal growth and first-lactation milk yields of Holstein cows. Journal of Dairy Science, v.83, n.1, p.23-29, 2000.

RADCLIFF, R.P.; VANDEHAAR, M.J.; KOBAYASHI, Y. et al. Effect of dietary energy and somatotropin on components of the somatotropic axis in Holstein heifers. Journal of Dairy Science, v.87, p.1229-1235, 2004.

RADCLIFF, R.P.; VANDEHAAR, M.J.; SKIDMORE, A.L. et al. Effects of diet and bovine somatotropin on heifer growth and mammary development. Journal of Dairy Science, v. 80 , p.1996-2003, 1997.

SEJRSEN, K.; FOLDAGER, J.; SORENSEN, M.T. et al. Effect of exogenous bovine somatotropin on pubertal mammary development in heifers. Journal of Dairy Science, v.69, p.1528-1535, 1986.

SEJRSEN, K.; HUBER, J.T.; TUCKER, H.A. Influence of amount fed on hormone concentrations and their relationship to mammary growth in heifers. Journal of Dairy Science, v.66, p.845-855, 1983.

SEJRSEN, K.; PURUP, S. Influence of prepubertal feeding level on milk yield potential of dairy heifers: a review. Journal of Animal Science, v.75, p.828-835, 1997.

SEJRSEN, K.; PURUP, S.; VESTERGAARD, M. et al. High body weight gain and reduced mammary growth: physiological basis and implications for milk yield potential. Domestic Animal Endocrinology, v.19, p.93-104, 2000. 
SILVA, L.F.P.; VANDEHAAR, M.J.; WEBER NIELSEN, M.S. et al. Evidence for a local effect of leptin in bovine mammary gland. Journal of Dairy Science, v.85, p.3277-3286, 2002a.

SILVA, L.F.P.; VANDEHAAR, M.J.; WHITLOCK, B.K. et al. Short communication: relationship between body growth and mammary development in dairy heifers. Journal of Dairy Science, v.85, p.2600-2602, 2002 b.

SMITH, J.L.; SHEFFIELD, L.G. Production an regulation of leptin in bovine mammary epithelial cells. Domestic Animal Endocrinology, v.22, p.145-154, 2002.

SWANSON, E.W. Effect of rapid growth with fattening of dairy heifers on their lactational ability. Journal of Dairy Science, v.43, p.377-387, 1960.

VESTERGAARD, M.; SEJRSEN, K.; FOLDAGER, J. et al. The effect of bovine growth hormone on growth, carcass composition, and meat quality of dairy heifers. Acta Agriculturae Scandinavica, v. 43, p. $165,1993$.
WALDO, D.R.; CAPUCO, A.V. Effects of feeding dairy heifers on growth and milk production. Davis: Animal Nutrition Conference, 1992. p.1.

WANG, T.; BROWN, M.J. mRNA quantificatiom by real-time TaqMan polymerase chain reaction: validation and comparison with RNAase protection. Analytical Biochemistry, v.169, p.198-201, 1999.

WEBER, M.S.; PURUP, M.; VESTERGAARD, M. et al. Contribution of insulin-like growth factor (IGF)-I and IGF-binding protein-3 to mitogenic activity in bovine mammary extracts and serum. Journal of Endocrinology, v.161, p.365-373, 1999.

WINER, J.; JUNG, C.K.; SHACKEL, I. et al. Development and validation of real-time quantitative reverse-transcriptase polymerase chain reaction for monitoring gene expression in cardiac myocytes in vitro. Analytical Biochemistry, v.270, p.41-49, 1999.

ZHANG, Y.; PROENCA, R.; MAFFEI, M. et al. Positional cloning of the mouse obese gene and its human homologue. Nature, v.372, p.425-432, 1994. 